\title{
The Role of Mathematical Competitions and Other Challenging Contexts in the Teaching and Learning of Mathematics
}

\author{
Mariade Losada and Ali Rejali
}

\section{Statement of Purpose}

The organizing group and the participants come to challenging mathematics from many different perspectives, but all firmly believe that mathematics education for the twenty-first century requires all teachers, schools and extra-curricular experiences to provide structure and support that allow and entice each student and citizen to strive to reach his or her personal best in mathematics. In the words of the discussion document for ICMI Study 16, "Mathematics is engaging, useful, and creative. What can we do to make it (engaging, useful and creative mathematics) accessible to more people?"

\section{Aims}

1. To gather teachers, mathematicians, mathematics educators, researchers and other congress participants who are interested in mathematical competitions and other challenging contexts in the teaching and learning of mathematics at all levels.

Organizers Co-chairs: Maria de Losada (Colombia), Ali Rejali (Iran); Team Members: Andy Liu (Canada), John Webb (South Africa), Jaroslav Svrcek (Czech Republic), Kyung Mi Choi (Korea); Liaison IPC Member: Petar Kenderov (Bulgaria).

\section{Losada ( $\square)$}

Universidad Antonio Nariño, Bogotá, Colombia

e-mail: mariadelosada@gmail.com

\author{
A. Rejali \\ Isfahan University of Technology, Isfahan, Iran \\ e-mail: a.rejali@yahoo.com \\ (C) The Author(s) 2015
}


2. To present research results and reports on activities that will allow the group to make an updated sketch of the state of the art, thus further developing the aims of the 16th ICMI Study, and colouring it in by addressing new trends and developments in research and practice in mathematics competitions and other challenging contexts and their effect on mathematics teaching and learning and in pinpointing research problems of special interest to the group.

In summary, the organizing team welcomed all contributions related to mathematical challenges, the state of the art, follow-up studies and the results of studies on the impact of these activities on mathematics education. The organizing team has asked those wishing to join the study group to submit a paper of between 1500 and 2500 words in length addressing issues highlighted or others that make a significant contribution to the aims and focus of the group, and they have also invited speakers to submit their papers to the WFNMC journal (http://www.amt.edu.au/wfnmc/ journal.html) for possible publication in a special issue.

\section{Questions that Could Have Been Addressed Were}

Do mathematical challenges better reflect the nature, the beauty and other characteristics of the corpus of elementary mathematics, as well as the experience of doing mathematics, than ordinary school mathematics? Does this make the mathematics involved more likely to engage the learners?

Does the widespread use of calculators and computers-marvelous tools that they are-imply that mathematics education can only justify itself (aside: in as much as it prepares the learner to use a calculator or computer in an intelligent fashion, or) in as much as it is challenging, non-routine and cannot trivially be done on a calculator or computer, that is, in as much as it provides opportunities for all learners to be engaged in challenging mathematics?

How does this last question apply to in-service and future teachers? What are the needs and characteristics of teacher education with regard to challenging mathematics?

What are the implications for more challenging assessment in mathematicsboth in and beyond the classroom?

Does the involvement of teachers in challenging contexts in and outside the classroom affect their behavior in their teaching mathematics?

Does the engagement of the learners in challenging contexts affect their learning ability in mathematics? 


\section{Realizations at ICME-12}

The organizing team recieved 25 contributions. Each contributed paper was reviewed by at least two referees. Finally 13 papers were accepted for presentation.

Contributions from participants from all continents addressed challenging mathematical experiences in many contexts. Unfortunately one of the contributors from India and one from Iran could not participate due to lack of funding and some contributors as well as members of the organizing team were unable to attend the Congress due to programming conflicts with IMO in Argentina, and their joint interest with other TSG's especially TSG 3 (Activities and programs for gifted students).

A joint paper, given by Emily Hobbs, Kings College London, (with David Stern and Michael Obiero Maseno University, Kenya, Zachariah Mbasu, Makhokho School, Kenya, Jeff Goodman, Lycee Francais Charles de Gaulle, UK, Tom Denton, York University, Canada) focused on the motivation challenging mathematics gives to students in Kenya to continue their studies on the university level. The talk was titled" Report on the 1st Maseno Maths Camp: a mathematics popularisation event in Kenya". It introduced a mathematics camp in Kenya, developed from the need to create a forum where mathematics could be discussed and explored at the secondary level in such a way as to show that there is more to mathematics than calculations and correct answers, mentioning that the aim of the camp was to expose young minds to new ideas in mathematics relevant to the world they live in. They reported a one-week programme which was developed for school students focusing on problem solving, promoting play, experimentation, and using computers to explore mathematical ideas. Their goal was to spark a life-long love for mathematics in students, which will both improve their performance in school and increase the chances that they will pursue mathematics and science in the longer term. They mentioned that participation of school teachers was also encouraged in order to expose them to innovative teaching methods and computer resources. The structure and content of the 1st Maseno Maths Camp 2011, the future of this camp and plans for Mini Maths Camps around schools in Kenya were explained in this presentation.

From India, we learned of challenging mathematics for students from deprived backgrounds through the paper titled "Turning Tension into Thrill (of joy), Tournament as a Tool - a case study" prepared by Arundhati Mukherjee, The New Horizon School, India. The speaker was unable to attend ICME12, but her contribution remains part of the scene sketched there.

The use of the Internet in reaching out to students with mathematical challenges was highlighted by Susana Carreira, Sciences and Technology, University of Algarve, Portugal in conjunction with Nelia Amado, of the same university and Rosa Antonia Tomas Ferreira, from the University of Coimbra, Portugal, as well as Jaime Silva, also from the University of Coimbra in their paper titled "A web-based mathematical problem solving competition in Portugal: Strategies and approaches". After each problem is posted students have two weeks to submit their answers 
either through their personal e-mail or on the webpage platform. As speaker Susana Carreira mentioned some more details of the competition and discussed the results. Mark Applebaum of Kaye Academic College of Education, Israel, (in a paper prepared jointly with Margo Kondratieva, Memorial University, Canada and Viktor Freiman, University de Moncton, Canada,) gave results from the Virtual Mathematical Marathon, addressing student and family participation, and the general enthusiasm it has raised especially in Israel's Jewish community. The study, although not the presentation itself, concentrated on the following questions: what are participation patterns in an online problem-solving competition by boys and girls and how successful were participants according to the gender, and how their intermediate result related to their further participation in the event.

In a related theme, Yahya Tabesh from the Sharif University of Technology in Iran (along with Abbas Mousavi of the same institution) explained an internet resource that allows students to search and learn from ingenious solutions published on the Internet He introduced a new tool called "How to iSolve It!" which develops problem solving over the net as a smart system. He mentioned that iSolve is a reference system for problem solving which through a wiki on a social network would develop skills. He explained that the system could be referred on the net as a retrieval information system with smart algorithms which lead to more advanced results. Finally he introduced the iSolve system properly and some pilot results were also presented in his talk.

"Developing a much more challenging curriculum for all" was the theme treated by María de Losada of the Universidad Antonio Nariño, Bogotá, Colombia, a proposal to make challenging mathematics an integral part of the mathematics curriculum. In her presentation she reported on research regarding the construction of a much more challenging curriculum for students of grade six, based on her and her colleagues' own research as well as that of many other mathematics educators who have analyzed basic research, the panorama of failure and the spectrum of success.

Alexander Soifer from the University of Colorado, USA, brought the group's attention to the relationship between mathematical challenges and research in mathematics itself in his talk titled "The goal of mathematics education, including competitions, is to let students touch "real mathematics"; We ought to build that bridge". Professor Soifer maintained that as in "real" mathematics, Olympiad problems ought to include not just deductive reasoning, but also experimentation, construction of examples, synthesis in a single problem of ideas from various branches of mathematics, open ended problems, and even open problems. Olympiad problems should merit such epithets as beautiful and counter-intuitive. He explained problem creation and research subjects drawn from problems in competitions and connections between the following: mathematics olympiads, open problems, synthesis, construction, example, and mathematics, research.

From the Russian Federation the group had the experience of listening to the paper "South Mathematical Tournament: Tasks and Organization Hints" read by Daud Mamiy from Adyghe State University written jointly with Nazar Agakhanov, Moscow Institute of Physics and Technology. As the title implies an innovative 
tournament nevertheless true to the traditional roots of original and challenging problem solving gave many new ideas to the participants of TSG 34. The South Mathematical Tournament has been held in Orlyonok Children's Recreational Center on the Caucasus Black Sea coast. The authors mentioned that the tournament has been administered and organized by Adyghe State University. The report showed that this tournament is a team mathematical contest structured as a series of mathematical battles between secondary school students representing various regions of Russia, that the team members are usually students who are well prepared and possess the experience of participation in competitions at various levels. In this presentation the authors claim that every year the tournament includes some of the winners and awardees of National and International Mathematics Olympiads and candidates to Russia's national mathematics team. The scheme and some of its problems were explained in detail in the presentation.

The experience of organizing a competition simulating investment strategies for university students of the administrative sciences was recounted by Yahya Tabesh in a paper titled PitGame and prepared in collaboration with Mohammad $\mathrm{H}$. Ghaffari Anjadani and Farzan Masrour,also of the Sharif University of Technology, Iran. He reported that PitGame minimizes the downsides and obstacles of contests through a sort of double creativity which seems to cause a fresh environment stressing the joy of problem solving. He mentioned that contests are mainly a competitive learning activity and it is usually on an extracurricular level that creativity and problem solving skills are developed. He claimed that competitive learning could assist educators in discovering students' abilities and creativity as well as improve students' skills, and that it would support improvement of the educational system too. He explained that this problem solving contest is based on competitive learning, game theory, and role playing.

Typical of research relating into the impact of participation in high-level mathematical problem-solving competitions, Kyung-Mi Choi of Korea and the University of Iowa, USA, in a paper prepared with Laurentius Susadya also of the University of Iowa informed the TSG34 group of "Impacts of Competition Experiences on Five IMO Winners from Korea".

\section{Conclusions}

Ali Rejali as one of the group's co-chairs opened the first session and María de Losada the second co-chair made the closing remarks. One theme running throughout the wide variety of experiences and research presented is the motivational quality of challenging mathematics on all levels, allowing each student to contribute his own ideas, benefit from the ideas of his peers and "own" the mathematics being developed through the solving of original and non-routine problems. A more challenging mathematics curriculum for all is being developed. Use of the Internet is becoming more prevalent, reaching out to students everywhere and sometimes getting families involved. Much research focuses on results 
analyzed by groups distinguished by gender, by level of competitivity, or by social and economic background. The heart of mathematical competitions are the problems created and posed, intimately related to the driving force in the creation of mathematics itself., but it is the students and teachers, and the transformation of their relationship to mathematics that drives the activity of this study group.

Open Access This chapter is distributed under the terms of the Creative Commons Attribution Noncommercial License, which permits any noncommercial use, distribution, and reproduction in any medium, provided the original author(s) and source are credited. 